\title{
Artigo Original / Original Paper \\ Protocolo para germinação assimbiótica e desenvolvimento inicial de protocormos de orquídeas nativas do Cerrado brasileiro
}

\author{
Protocol for asymbiotic germination and initial protocorm development of Brazilian Cerrado \\ native orchids
}

\author{
Jackeline Schultz Soares ${ }^{1,2,3}$, José Carlos Sorgato ${ }^{1}$ \& Luan Marlon Ribeiro ${ }^{1}$
}

\begin{abstract}
Resumo
Devido ao extrativismo, Orchidaceae apresenta elevada vulnerabilidade, necessitando de medidas para a conservação de suas espécies. Assim, objetivou-se determinar um protocolo para germinação e estabelecimento inicial de Cattleya nobilior, Cattleya lundii e Brassavola tuberculata quanto à desinfestação de sementes e a utilização de meios de cultura. Sementes foram desinfestadas em solução de $\mathrm{NaClO}$ a $0,8 \%$, por 5 min ou $15 \mathrm{~min}$, recebendo ou não tríplice lavagem. Em seguida, foram semeadas nos meios MS, MS 1/2, K ou VW. Posteriormente, foram transferidas para sala de crescimento com temperatura e fotoperíodo controlados. A porcentagem de germinação e o estabelecimento inicial das espécies estudadas foram avaliados 45 dias após a semeadura. Para todas as espécies, as sementes desinfestadas por 5 min e submetidas à tríplice lavagem apresentaram maiores \%G. Dessa forma, recomenda-se para a germinação in vitro e desenvolvimento inicial de protocormos das espécies $C$. nobilior e $B$. tuberculata, a utilização do tempo de desinfestação de 5 min, seguido da tríplice lavagem e semeadura em meio MS $1 / 2(\% \mathrm{G}=100$ e $72,8 \%$, propágulos em estágios 3 e 2, respectivamente). Para C. lundii, a semeadura deve ser realizada em meio KC, com a desinfestação por 5 min e tríplice lavagem das sementes $(\% \mathrm{G}=95,8 \%$ e propágulos em estágio 2$)$.

Palavras-chave: agente desinfestante, conservação da biodiversidade, espécies nativas, meios de cultura, Orchidaceae.

Abstract

Due to the extractivism Orchidaceae presents high vulnerability, needing measures for the conservation of its species. The aim of this study was to determine a protocol for germination and initial protocorm development of Cattleya nobilior, Cattleya lundii and Brassavola tuberculata for seed disinfestation and the use of culture media. Seeds were disinfested in $0.8 \% \mathrm{NaClO}$ solution by $5 \mathrm{~min}$ or $15 \mathrm{~min}$, receiving or not triple-wash. They were then sowing in MS, $1 / 2 \mathrm{MS}$, K or VW culture media. Subsequently, they were transferred to growth room with controlled temperature and photoperiod. The percentage of germination and initial development of the species studied were evaluated 45 days after sowing. For all species, the seeds disinfested by $5 \mathrm{~min}$ and submitted to the triple-wash showed higher germination percentage. Thus, is recommended the use of the 5 min disinfestation time, followed by the practice of triple-wash and sowing in 1/2 MS medium, for the germination and in vitro initial establishment of C. nobilior and B. tuberculata $(\% \mathrm{G}=100$ and $72.8 \%$ and seedlings in stages 3 and 2, respectively). For $C$. lundii, sowing should be done in $\mathrm{KC}$ medium, with 5 min disinfestation and triple-wash $(\% \mathrm{G}=95.8 \%$ and seedlings in stage 2$)$.
\end{abstract}

Key words: disinfestation agent, biodiversity conservation, native species, culture media, Orchidaceae.

\footnotetext{
${ }^{1}$ Universidade Federal da Grande Dourados, Faculdade de Ciências Agrárias, Rod. Dourados-Itahum, km 12, Cidade Universitária, C.P. 533, 79804-970, Dourados, MS, Brasil.

${ }^{2}$ ORCID: <https://orcid.org/0000-0001-9497-2975>

${ }^{3}$ Autor para correspondência: jacke.schultz@gmail.com
} 


\section{Introdução}

A família Orchidaceae abrange $70 \%$ das epífitas vasculares, típicas de florestas tropicais e subtropicais úmidas (Pridgeon et al. 2009), e tem sido apontada como a terceira mais representativa da biodiversidade vegetal do Cerrado (Batista et al. 2005; Mendonça et al. 2008). Nesse domínio fitogeográfico é composta por 705 espécies distribuídas em 125 gêneros (Barros et al. 2018).

Dentre essas espécies, destacam-se Cattleya nobilior Rchb.f., que apresenta hábito rupícola ou epífita, com flores rosa/escuro ou rosa claro/lilás e labelo em formato trilobado e pequeno porte (5 até $10 \mathrm{~cm})$ (BFG 2018). De acordo com a Flora do Brasil (Barros et al. 2018) a espécie é nativa, porém não endêmica do Brasil, com distribuição nas Regiões Norte, Nordeste e Centro Oeste. Já a Cattleya lundii (Rchb.f. \& Warm.) Van den Berg é uma espécie epífita, nativa e endêmica do Cerrado brasileiro, de pequeno porte (pseudobulbos até $5 \mathrm{~cm}$ ), possui flores de coloração branca com labelo em formato trilobado, com distribuição geográfica no Centro-Oeste, Sudeste e Sul (BFG 2018; Barros et al. 2018). Outra espécie nativa, porém não endêmica do Cerrado é a Brassavola tuberculata Hook., com hábito rupícola ou epífita, possui flores de coloração branca, e porte médio (10 cm até $1 \mathrm{~m}$ de comprimento), com distribuição geográfica no norte, nordeste, sudeste e sul do Brasil (BFG 2018; Barros et al. 2018).

Segundo Pedroso-de-Moraes et al. (2010) e Schuster et al. (2010), as orquídeas são excelentes bioindicadores ambientais, pois são sensíveis às interferências antrópicas, em virtude da ocupação de nichos especializados, sendo as primeiras plantas a serem afetadas pela degradação ambiental e as últimas a se instalarem nas áreas em restauração.

Essas plantas possuem o ciclo de vida especializado, suas sementes apresentam pouca ou nenhuma reserva nutritiva, e a germinação em ambiente natural é dependente da associação com fungos micorrízicos, o que, somado à coleta indiscriminada, resulta na vulnerabilidade da família, que está entre as mais seriamente ameaçadas de extinção (Faria et al. 2012).

A extração de orquídeas nativas constitui um dos principais fatores para a diminuição das populações do Cerrado. Nesse sentido, dentre as técnicas de cultivo in vitro, a germinação assimbiótica é uma ferramenta biotecnológica importante para a obtenção de plantas visando à preservação das espécies, pois possibilita a obtenção de um grande número de plantas, com variabilidade genética, em tempo relativamente curto e com alta qualidade fitossanitária (Ferreira \& Suzuki 2008; Suzuki et al. 2012; Cardoso 2014).

No entanto, a contaminação do material vegetal por fungos e bactérias pode interferir no sucesso da germinação assimbiótica. Uma das formas de evitar este problema é a desinfestação das sementes com hipoclorito de sódio $(\mathrm{NaClO})$ (Campos 2002; Faria et al. 2012; Silva et al. 2015). Porém, algumas sementes de Orchidaceae apresentam-se susceptíveis ao $\mathrm{NaClO}$, acarretando baixa porcentagem de germinação, devido a toxicidade (Chu \& Mudge 1994; Alvarez-Pardo et al. 2006).

Outro fator determinante na germinação e estabelecimento in vitro das plântulas é a escolha do meio de cultura, pois as formulações dos diferentes meios de cultivo são fatores categóricos nas respostas do material vegetal propagado (Faria et al. 2012; Paul et al. 2012).

Embora a semeadura assimbiótica seja muito utilizada e difundida entre os pesquisadores e produtores de orquídeas, o conhecimento disponível a respeito de protocolos de propagação ainda é restrito a algumas espécies, especialmente as de maior valor comercial (Hossain 2008; Schneiders et al. 2012; Sorgato 2016). Assim, informações sobre protocolos de multiplicação para espécies de orquídeas do Cerrado ainda são pouco desenvolvidos, evidenciando a necessidade de trabalhos na área de germinação, multiplicação, conservação e melhoramento genético para tais espécies (Carneiro 2015; Silva et al. 2016).

Dessa forma objetivou-se com este trabalho determinar um protocolo para germinação in vitro e desenvolvimento inicial de protocormos de Cattleya nobilior, Cattleya lundii e Brassavola tuberculata, quanto à desinfestação de sementes e a utilização de meios de cultura.

\section{Material e Métodos}

Foram utilizados como material de estudo, frutos maduros, ainda fechados, oriundos da polinização manual das espécies de orquídeas Cattleya nobilior, Cattleya lundii e Brassavola tuberculata, provenientes de matrizes com mais de oito anos. Essas foram cultivadas em viveiro $\left(22^{\circ} 11^{\prime} 53,2^{\prime \prime} \mathrm{S}, 54^{\circ} 56^{\prime} 02,3^{\prime \prime} \mathrm{W}\right)$ coberto pela sobreposição de duas telas de sombreamento de $50 \%$ (radiação fotossintética média $=235$ $\left.\mu \mathrm{mol} \mathrm{m} \mathrm{m}^{-2} \mathrm{~s}^{-1} / 12 \mathrm{~h} / \mathrm{dia}\right)$, sob condições médias 
de temperatura e umidade relativa de 22,6 $\pm 5{ }^{\circ} \mathrm{C}$ e $73,9 \pm 10 \%$ e provido de irrigação por microaspersão, constituído de difusores, posicionados um metro acima das plantas, acionados automaticamente por temporizador digital, sendo realizadas irrigações diárias, que totalizaram uma lâmina de água de $1 \mathrm{~mm} \mathrm{dia}{ }^{-1}$.

Os frutos, nove meses após a polinização, foram destacados das matrizes com auxílio de uma tesoura de poda manual e levados para o Laboratório de Cultivo in vitro da Universidade Federal da Grande Dourados-UFGD, onde foram desinfestados com solução de álcool etílico $70 \%$. Em seguida, dois frutos de cada espécie foram abertos com auxílio de bisturi e as sementes retiradas, homogeneizadas e acondicionadas em dessecador com sílica gel $\left(25 \pm 2{ }^{\circ} \mathrm{C} ; 75 \%\right.$ UR $)$ por 14 dias. Após a dessecação, as sementes de cada espécie foram embaladas separadamente em papel alumínio e armazenadas, por 180 dias, sob refrigeração $\left(5 \pm 2{ }^{\circ} \mathrm{C}\right) \mathrm{em}$ frascos de polipropileno providos de tampa com sílica gel.

Foram utilizados, como meio de cultura para germinação das sementes, os meios MS (Murashige \& Skoog 1962); MS1/2 (MS na metade da concentração de macro e micronutrientes); KC (Knudson 1946) e VW (Vacin \& Went 1949). Os meios de cultivo foram solidificados com 6,0 $\mathrm{g} \mathrm{L}^{-1}$ de ágar bacteriológico (Himedia ${ }^{\circledR}$, Índia) e suplementados com $30 \mathrm{~g} \mathrm{~L}^{-1}$ de sacarose. $\mathrm{O}$ $\mathrm{pH}$ dos meios foi aferido e ajustado para 5,8 utilizando-se $\mathrm{KOH}(0,1 \mathrm{M})$ e na sequência foram distribuídos em frascos de polipropileno com tampa rosqueável e capacidade de $50 \mathrm{~mL}$, sendo que cada frasco recebeu $20 \mathrm{~mL}$ de meio de cultivo. Posteriormente, os frascos foram esterilizados em autoclave a $120{ }^{\circ} \mathrm{C}$ e $1 \mathrm{~atm}$ de pressão, por 20 minutos. Após a solidificação dos meios os mesmos foram transferidos para ambiente estéril.

Para a confirmação da viabilidade, amostras de sementes de cada espécie foram submetidas ao teste de tetrazólio, seguindo metodologia proposta por Soares et al. (2014). Após a confirmação da viabilidade foram pesadas quatro amostras de 5 mg de sementes de cada espécie. As amostras foram levadas para ambiente asséptico, em câmara de fluxo laminar, e desinfestadas com 15 $\mathrm{mL}$ de solução de hipoclorito de sódio a $0,8 \%$. Duas amostras de cada espécie permaneceram imersas na solução por 5 minutos $(5 \mathrm{~min})$ e duas por 15 minutos (15 min). Após os períodos estabelecidos, as suspensões de sementes foram diluídas para $50 \mathrm{~mL}$ com água destilada estéril.
Em seguida, uma amostra de cada espécie e de cada tempo de desinfestação foi utilizada imediatamente para a semeadura in vitro. $\mathrm{O}$ $\mathrm{pH}$ dessas amostras foi aferido com auxílio de pHmetro digital, apresentando o valor de $10,8 \pm 0,3$. As amostras restantes receberam tríplice lavagem com água destilada estéril (40 $\mathrm{mL}$ por lavagem), sendo essa removida depois de cada lavagem e, após este procedimento o volume dessas suspensões foi completado para $50 \mathrm{~mL}$ com água destilada estéril para a semeadura in vitro. Foi utilizado um pipetador automático, inoculando-se $1.000 \mu \mathrm{L}$ da suspensão de sementes por frasco de cultivo. Após a inoculação, as culturas foram acondicionadas em sala de crescimento com temperatura e fotoperíodo controlados $\left(25 \pm 2{ }^{\circ} \mathrm{C} ; 16 \mathrm{~h}\right)$ e irradiância de $22,8 \mu \mathrm{mol} \mathrm{m}^{-2} \mathrm{~s}^{-1}$ propiciada por lâmpadas fluorescentes brancas.

Quarenta e cinco dias após a semeadura foi avaliada a porcentagem de germinação das espécies pesquisadas. Foram contados o número de sementes não germinadas (NS) e o número de protocormos clorofilados (NPC). A porcentagem de germinação $(\% \mathrm{G})$ foi calculada pela seguinte expressão: $\% \mathrm{G}=[\mathrm{NPC} /(\mathrm{NS}+$ $\mathrm{NPC})] \times 100$. Após a contagem da germinação, as avaliações visuais de estabelecimento inicial foram realizadas seguindo metodologia descrita por Suzuki et al. (2010), sendo consideradas as seguintes classes morfológicas: Estágio 1 = protocormo intumescido clorofilado; Estágio 2 = plântula com formação da primeira folha; Estágio 3 = plântula com duas folhas e Estágio 4 = plântula com folhas e uma ou mais raízes. Após as avaliações, os tratamentos foram fotografados com câmera acoplada ao microscópico estereoscópico, com auxílio do programa computacional AxionVision versão $3.1\left(\right.$ Zeiss $\left.^{\circledR}\right)$.

O delineamento experimental utilizado foi inteiramente casualizado e os tratamentos arranjados em esquema fatorial $2 \times 2 \times 4$ (dois tempos de desinfestação, dois tipos de lavagem [com ou sem tríplice lavagem] e quatro meios de cultura), com quatro repetições constituídas de um frasco de cultivo. Os resultados da porcentagem de germinação foram transformados para $\sqrt{ }(\mathrm{x}+1)$ e, a seguir, submetidos à análise de variância e as médias comparadas pelo teste de Tukey $(\mathrm{p}<0,05)$, com auxílio do programa SISVAR (Programa de Análises Estatísticas v.5.3. Universidade Federal de Lavras, MG). 


\section{Resultados e Discussão}

De maneira geral, houve efeito conjunto e isolado para todas as variáveis analisadas. A interação tripla tempo de desinfestação (TD) $\times$ tipo de lavagem $(\mathrm{TL}) \times$ meio de cultura $(\mathrm{MC})$ foi significativa para as espécies Cattleya lundii ( $\mathrm{p}<$ $0,05)$ e Brassavola tuberculata $(\mathrm{p}<0,01)$. Para C. nobilior, apenas as interações TD $\times$ TL e TL $\times$ MC apresentaram significância estatística ( $\mathrm{p}<$ 0,01) (Tab. 1).

Tabela 1 - Resumo da análise de variância da porcentagem de germinação de sementes de Cattleya nobilior, Cattleya lundii e Brassavola tuberculata.

Table 1 - Summary of variance analysis of the percentage of seed germination of Cattleya nobilior, Cattleya lundii and Brassavola tuberculata.

Fonte de variação

Porcentagem de germinação

\begin{tabular}{|c|c|c|c|c|}
\hline & \multirow[b]{2}{*}{ G.L. } & \\
\hline & & Cattleya nobilior & Cattleya lundii & Brassavola tuberculata \\
\hline Tempo de desinfestação (TD) & 1 & $21,04^{\mathrm{ns}}$ & $66,61^{*}$ & $3755,31^{* *}$ \\
\hline Tipo de lavagem (TL) & 1 & $83180,32^{* *}$ & $92758,01^{* *}$ & $34854,32^{* *}$ \\
\hline Meio de cultura (MC) & 3 & $444,61^{* *}$ & $1325,07^{* *}$ & $123,10^{* *}$ \\
\hline $\mathrm{TD} \times \mathrm{TL}$ & 1 & $136,42^{* *}$ & $128,36^{* *}$ & $3216,69^{* *}$ \\
\hline $\mathrm{TD} \times \mathrm{MC}$ & 3 & $18,13^{\mathrm{ns}}$ & $133,64^{* *}$ & $42,36^{*}$ \\
\hline $\mathrm{TL} \times \mathrm{MC}$ & 3 & $456,63^{* *}$ & $1116,37^{* *}$ & $113,90^{* *}$ \\
\hline $\mathrm{TD} \times \mathrm{TL} \times \mathrm{MC}$ & 3 & $33,71^{\mathrm{ns}}$ & $86,12^{* *}$ & $32,21^{*}$ \\
\hline Erro & 45 & 16,42 & 13,13 & 13,80 \\
\hline C.V. $(\%)$ & & 6,49 & 6,45 & 15,46 \\
\hline Média Geral & & 62,42 & 56,14 & 24,03 \\
\hline
\end{tabular}

$\mathrm{GL}=$ graus de liberdade; $* *$ significativo $(\mathrm{p}<0,01) ; *$ significativo $(\mathrm{p}<0,05)$, pelo teste $\mathrm{F}$.

Não foi observada contaminação nos frascos de cultivo e, para as espécies estudadas, independente do meio de cultura ou do tempo de desinfestação, as sementes quando submetidas à tríplice lavagem, apresentaram porcentagem de germinação $(\% \mathrm{G})$ superiores àquelas que não receberam este procedimento.

Na espécie $C$. lundii, o tempo de desinfestação de 5 min propiciou maior $\% \mathrm{G}$, com média geral de $57,1 \%$, enquanto o tempo de $15 \mathrm{~min}$ apresentou $55,1 \%$, sendo estatisticamente inferior. Quando essas sementes foram submetidas a tríplice lavagem, apresentaram $\% \mathrm{G}$ maiores $(\% \mathrm{G}=96,6 \%$ e $91,7 \%$ com 5 min e 15 min de desinfestação, respectivamente) do que as observadas naquelas que não foram submetidas a esse processo $(\% \mathrm{G}=$ $17,6 \%$ e $18,4 \%$ ). No que se refere a interação TD $\times \mathrm{TL} \times \mathrm{MC}$, as maiores $\% \mathrm{G}$ foram observadas em meio VW, seguido do MS 1/2, KC e MS, com 5 min de desinfestação em $\mathrm{NaClO}$ e tríplice lavagem das sementes $(\% \mathrm{G}=98,4 \% ; \% \mathrm{G}=96,7 \% ; \% \mathrm{G}=95,8 \%$ e $\% \mathrm{G}=95,6 \%$, respectivamente), sem diferença estatística entre todos os meios utilizados (Tab. 2).

Observou-se, para B. tuberculata, que o tempo de 5 min também apresentou as maiores $\% \mathrm{G}(62,0 \%$ e $1,2 \%$, com e sem tríplice lavagem, respectivamente), sendo superior ao tempo de 15 $\min (\% \mathrm{G}=32,5 \%$ e $0,1 \%)$. Em relação ao tipo de lavagem, as sementes submetidas a tríplice lavagem apresentaram $\% \mathrm{G}$ maiores do que aquelas não submetidas a esse procedimento. Com relação aos meios de cultura, de maneira geral, todos acarretaram baixas \%G. Para essa espécie, a maior $\% \mathrm{G}$ foi observada em meio MS $1 / 2$ quando as sementes foram desinfestadas por $5 \mathrm{~min}$ e submetidas à tríplice lavagem $(\% \mathrm{G}=72,8)(\mathrm{Tab} .2)$. 
Tabela 2 - Porcentagem de germinação de sementes de Cattleya lundii e Brassavola tuberculata em função do meio de cultura, do tipo de lavagem $(\mathrm{CL}=$ com lavagem; $\mathrm{SL}=$ sem lavagem) e do tempo de desinfestação das sementes. Table 2 - Percentage of seed germination of Cattleya lundii and Brassavola tuberculata $(\mathrm{CL}=$ with washing, $\mathrm{SL}=$ without washing) and the time of disinfestation of the seeds.

\begin{tabular}{|c|c|c|c|c|}
\hline \multicolumn{5}{|c|}{ Cattleya lundii } \\
\hline & \multicolumn{4}{|c|}{ \% de Germinação } \\
\hline & \multicolumn{2}{|c|}{$\mathrm{TE}=5$ minutos } & \multicolumn{2}{|c|}{$\mathrm{TE}=15$ minutos } \\
\hline Meios de cultura & $\mathrm{CL}$ & SL & $\mathrm{CL}$ & SL \\
\hline $\mathrm{KC}$ & $95,8 \mathrm{aA}^{\mathrm{a}}$ & $34,9 \mathrm{bB}^{\mathrm{a}}$ & $93,3 \mathrm{aA}^{\mathrm{a}}$ & $48,1 \mathrm{aB}^{\mathrm{a}}$ \\
\hline MS & $95,6 \mathrm{aA}^{\mathrm{a}}$ & $5,9 \mathrm{aB}^{\mathrm{c}}$ & $87,9 \mathrm{bA}^{\mathrm{a}}$ & $5,0 \mathrm{aB}^{\mathrm{c}}$ \\
\hline MS $1 / 2$ & $96,7 \mathrm{aA}^{\mathrm{a}}$ & $3,0 \mathrm{aB}^{\mathrm{c}}$ & $92,3 \mathrm{aA}^{\mathrm{a}}$ & $5,5 \mathrm{aB}^{\mathrm{c}}$ \\
\hline VW & $98,4 \mathrm{aA}^{\mathrm{a}}$ & $26,7 \mathrm{aB}^{\mathrm{b}}$ & $93,5 \mathrm{aA}^{\mathrm{a}}$ & $15,0 \mathrm{bB}^{\mathrm{b}}$ \\
\hline Média Geral & 96,6 & 17,6 & 91,7 & 18,4 \\
\hline C.V. $(\%)$ & \multicolumn{4}{|c|}{6,45} \\
\hline \multicolumn{5}{|c|}{ Brassavola tuberculata } \\
\hline & \multicolumn{4}{|c|}{ \% de Germinação } \\
\hline & \multicolumn{2}{|c|}{$\mathrm{TE}=5$ minutos } & \multicolumn{2}{|c|}{$\mathrm{TE}=15$ minutos } \\
\hline Meios de cultura & $\mathrm{CL}$ & SL & $\mathrm{CL}$ & SL \\
\hline $\mathrm{KC}$ & $61,9 \mathrm{aA}^{\mathrm{b}}$ & $1,1 \mathrm{aB}^{\mathrm{a}}$ & $28,3 \mathrm{bA}^{\mathrm{b}}$ & $0,1 \mathrm{aB}^{\mathrm{a}}$ \\
\hline MS & $55,5 \mathrm{aA}^{\mathrm{b}}$ & $0,2 \mathrm{aB}^{\mathrm{a}}$ & $34,0 \mathrm{bA}^{\mathrm{ab}}$ & $0,0 \mathrm{aB}^{\mathrm{a}}$ \\
\hline MS $1 / 2$ & $72,8 \mathrm{aA}^{\mathrm{a}}$ & $1,6 \mathrm{aB}^{\mathrm{a}}$ & $38,1 \mathrm{bA}^{\mathrm{a}}$ & $0,1 \mathrm{aB}^{\mathrm{a}}$ \\
\hline VW & $58,1 \mathrm{aA}^{\mathrm{b}}$ & $1,9 \mathrm{aB}^{\mathrm{a}}$ & $29,9 \mathrm{bA}^{\mathrm{b}}$ & $0,2 \mathrm{aB}^{\mathrm{a}}$ \\
\hline Média Geral & 62,0 & 1,2 & 32,5 & 0,1 \\
\hline C.V. $(\%)$ & & & & \\
\hline
\end{tabular}

Letras maiúsculas, na linha, comparam os tipos de lavagem (CL ou SL) no mesmo tempo de desinfestação (5 min ou 15 min) e no mesmo meio de cultura (Tukey $\mathrm{p}<0,05$ ).

Letras minúsculas, na linha, comparam o mesmo tipo de lavagem (CL ou SL), nos diferentes tempos de desinfestação (5 min ou 15 min), em relação ao mesmo meio de cultura (Tukey $\mathrm{p}<0,05$ ).

Letras sobrescritas, na coluna, comparam o meio de cultura no mesmo tipo de lavagem (CL ou SL), em relação ao tempo de desinfestação (5 min ou 15 min) (Tukey $\mathrm{p}<0,05)$.

Para a $C$. nobilior, os resultados analisados demonstraram que, quando as sementes foram submetidas a tríplice lavagem, apresentaram os maiores valores de germinação, com média de $98,5 \%$, enquanto aquelas que não passaram por esse procedimento apresentaram $\% \mathrm{G}=26,4 \%$. Em relação à interação TD $\times$ TL, quando as sementes foram desinfestadas por 5 min e submetidas à tríplice lavagem, foi observada a maior $\% \mathrm{G}$ $(99,4 \%)$, valor estatisticamente superior quando comparado à média obtida no mesmo tempo de desinfestação, porém sem tríplice lavagem $(\% \mathrm{G}=$ $24,3 \%$ ) e estatisticamente igual ao observado no tempo de 15 min com lavagem (97,9\%) (Tab. 3).
Quanto à interação TL $\times$ MC, para essa espécie, as maiores $\% \mathrm{G}$ foram observadas em meio MS $1 / 2$ com a tríplice lavagem das sementes $(\% \mathrm{G}=100 \%)$, não diferindo estatisticamente dos meios MS, VW e $\mathrm{KC}$, que propiciaram $98,3 \%, 98,1 \%$ e $97,5 \%$ de germinação, respectivamente (Tab. 4).

De acordo com Arditti \& Ernst (1992), a aplicação de solução de hipoclorito de sódio de 5 min a 30 min permite uma desinfestação por completo das sementes, resolvendo assim o problema da contaminação. No entanto, o tipo e a concentração do agente desinfestante são fatores que determinam esse tempo de exposição das sementes de orquídeas para semeadura in vitro. 
Tabela 3 - Porcentagem de germinação de sementes Cattleya nobilior, em função do tipo de lavagem $(\mathrm{CL}=\mathrm{com}$ lavagem; SL = sem lavagem) e do tempo de desinfestação das sementes.

Table 3 - Percentage of seed germination of Cattleya nobilior, according to the type of washing (CL = with washing; SL = without washing) and the time of disinfestation of the seeds.

\begin{tabular}{lcc}
\hline \multicolumn{3}{c}{$\begin{array}{c}\text { Cattleya nobilior } \\
\text { \% de Germinação }\end{array}$} \\
\hline Tipo de desinfestação & CL & SL \\
5 minutos & $99,4 \mathrm{aA}$ & $24,3 \mathrm{bB}$ \\
15 minutos & $97,9 \mathrm{aA}$ & $28,4 \mathrm{bA}$ \\
Média Geral & 98,5 & 26,4 \\
C.V. (\%) & & \\
\hline
\end{tabular}

Letras minúsculas, na linha, comparam o tipo de lavagem (CL ou SL) no mesmo tempo de desinfestação (5 min ou 15 min) (Tukey p $<0,05)$.

Letras maiúsculas, na coluna, comparam o tempo de desinfestação ( 5 min ou 15 min), no mesmo tipo de lavagem (CL ou SL) (Tukey p < 0,05).

$\mathrm{O} \mathrm{NaClO}$ é um alcalóide que atua inativando microrganismos aeróbicos e esporos de fungos, que são responsáveis pela maior parte das contaminações. Sua ação é decorrente da perda de $\mathrm{Cl}^{-}$, que ativa a oxidação de íons que captura moléculas de oxigênio (Alvarez-Pardo et al. 2006). Essa técnica de desinfestação tem sido eficaz na maioria dos casos, porém, algumas espécies de Orchidaceae apresentam sementes mais sensíveis ao hipoclorito de sódio, que pode se tornar tóxico, ocasionando baixa porcentagem de germinação em meio de cultivo (Chu \& Mudge 1994; Oddie et al. 1994; Sorgato et al. 2020). Assim, a redução na $\% \mathrm{G}$ das sementes de todas as espécies estudadas, quando não foi realizada a tríplice lavagem, pode estar relacionada ao hipoclorito de sódio.

Embora Faria et al. (2012) recomende a utilização da solução de hipoclorito de sódio a $0,5 \%$ por 15 min para a descontaminação de sementes de orquídeas antes da semeadura in vitro, os resultados observados neste trabalho demonstraram que o tempo de exposição das sementes de orquídeas ao $\mathrm{NaClO}$ por 5 min proporcionou melhores condições para a maior \%G.

Dessa forma, o tempo de desinfestação de sementes de $C$. nobilior, $C$. lundii e $B$. tuberculata pode ser reduzido para $5 \mathrm{~min}$, com a utilização de hipoclorito de sódio a $0,8 \%$, e com a lavagem

Tabela 4 - Porcentagem de germinação de sementes Cattleya nobilior, em função do meio de cultura e do tipo de lavagem $(\mathrm{CL}=$ com lavagem; $\mathrm{SL}=$ sem lavagem $)$ das sementes.

Table 4 - Percentage of germination of Cattleya nobilior seeds, as a function of the culture medium and the type of washing $(C L=$ with washing; $\mathrm{SL}=$ without washing) of the seeds.

\begin{tabular}{lcc}
\hline \multicolumn{1}{c}{$\begin{array}{c}\text { Cattleya nobilior } \\
\text { \% de Germinação }\end{array}$} \\
\hline Meios de cultura & CL & SL \\
KC & $97,5 \mathrm{aA}$ & $32,4 \mathrm{bAB}$ \\
MS & $98,3 \mathrm{aA}$ & $10,9 \mathrm{bC}$ \\
MS $1 / 2$ & $100,0 \mathrm{aA}$ & $28,20 \mathrm{bB}$ \\
VW & $98,1 \mathrm{aA}$ & $33,9 \mathrm{bA}$ \\
Média Geral & 98,5 & 26,4 \\
C.V. (\%) & & \\
\hline
\end{tabular}

Letras minúsculas, na linha, comparam o tipo de lavagem (CL ou SL) em relação ao mesmo meio de cultura (Tukey p <0,05).

Letras maiúsculas, na coluna, comparam os meios de cultura em relação ao mesmo tipo de lavagem (CL ou SL) (Tukey p < 0,05). 
das sementes, sem a ocorrência de contaminação dos meios de cultura e com aumento na $\% \mathrm{G}$ das espécies estudadas em relação ao tempo de $15 \mathrm{~min}$.

Alvarez-Pardo et al. (2006) relatam a importância do procedimento de lavagem das sementes com água destilada. Os autores salientam, ainda, que esse procedimento pode ser demorado, mas é necessário, após a embebição das sementes de orquídeas em solução de hipoclorito de sódio, realizar várias lavagens das sementes com água destilada estéril. Neste trabalho, foi possível observar que a utilização de três lavagens com água destilada estéril proporcionou aumento significativo na $\% \mathrm{G}$ de $C$. nobilior, $C$. lundii e $B$. tuberculata, demonstrando que o procedimento é imprescindível para a semeadura in vitro dessas espécies.

Outro fator importante na germinação de sementes é o $\mathrm{pH}$, que na literatura é recomendado entre 5,6 e 5,8 para os meios de cultura (Faria et al. 2012). A solução aquosa de $\mathrm{NaClO}$ utilizada para a semeadura in vitro, quando não realizada a tríplice lavagem, apresentou $\mathrm{pH}$ alcalino, em torno de 10,8, nos meios de cultura. Dessa forma, essa solução de $\mathrm{pH}$ elevado, em conjunto com os meios de cultura e em contato com as sementes, pode ter influenciado a germinação das espécies estudadas, como observado pelas menores $\% \mathrm{G}$ apresentadas quando não foi realizada a tríplice lavagem.

Segundo Abrão et al. (2014) e Sorgato et al. (2020), os meios de cultura como MS e MS 1/2, que possuem maiores concentrações de nutrientes, podem proporcionar aumento na germinação de espécies como Cattleya loddigesii Lindl. e Dendrobium Phalaenopsis Fitzg., respectivamente. No entanto, outros autores observaram que dependendo da espécie estudada, os meios como VW e KC que possuem menores concentrações de nutrientes, também podem proporcionar condições para a maior \%G (Dutra et al. 2009; Suzuki et al. 2010).

Os resultados de germinação, obtidos nesse trabalho, evidenciam que as espécies $C$. nobilior, C. lundii e B. tuberculata apresentaram \%G satisfatória tanto em meios de cultura com maiores concentrações de nutrientes, quanto naqueles com menor teor nutricional, evidenciando que pode haver maior influência da toxicidade do agente desinfestante ao qual foram submetidas do que do meio de cultura na germinação dessas espécies.

Na Figura 1, observa-se o estabelecimento inicial in vitro dos propágulos. Visualmente é possível perceber que, para C. nobilior, os meios de cultura MS e MS 1/2, ambos com maior valor nutricional, apresentaram protocormos maiores e plântulas mais desenvolvidas aos 45 dias, chegando aos estádios 2 (plântulas com formação da primeira folha) e 3 (plântulas com duas folhas), independente da realização ou não de tríplice lavagem das sementes. $\mathrm{Na}$ espécie $C$. lundii, pode-se observar que o meio de cultura KC (com baixo teor nutricional), em conjunto com a tríplice lavagem das sementes e a exposição ao agente desinfestante por $5 \mathrm{~min}$, propiciou maior desenvolvimento dos propágulos, apresentando plântulas em estádio 2. Em $B$. tuberculata, independente do meio utilizado, todos os propágulos oriundos de suspensão de sementes que recebeu a tríplice lavagem apresentaram-se em estádio 2. Porém, aqueles provenientes de sementes que permaneceram por $5 \mathrm{~min}$ em solução de $\mathrm{NaClO}$, receberam tríplice lavagem e germinaram em meio MS 1/2, apresentaram-se em estádio 3.

Esses resultados permitem inferir que, embora as espécies estudadas apresentem germinação satisfatória em todos os meios de cultivo utilizados, o estabelecimento inicial de protocormos e plântulas, além de ser influenciado pelo tempo de exposição à solução desinfestante e a realização ou não de tríplice lavagem, ainda está diretamente relacionado ao meio utilizado para o cultivo in vitro.

Dessa forma, recomenda-se para a germinação in vitro e desenvolvimento inicial dos protocormos das espécies $C$. nobilior e $B$. tuberculata, a utilização do tempo de desinfestação de 5 min, seguido da prática da tríplice lavagem da suspensão de sementes e a semeadura em meio MS $1 / 2$.

Já para $C$. lundii, recomenda-se para a germinação in vitro e desenvolvimento inicial dos protocormos, a semeadura em meio de cultivo $\mathrm{KC}$, com a utilização do tempo de desinfestação de 5 min e a prática da tríplice lavagem da suspensão de sementes.

\section{Agradecimentos}

Ao Laboratório de Cultivo in vitro da Universidade Federal da Grande Dourados-UFGD situado em Dourados-MS, o espaço e materiais fornecidos para a condução desse experimento; assim como à equipe técnica e aos estagiários, a colaboração no momento das avaliações.

À Coordenação de Aperfeiçoamento de Pessoal de Nível Superior (CAPES), a concessão da bolsa de estudo. 


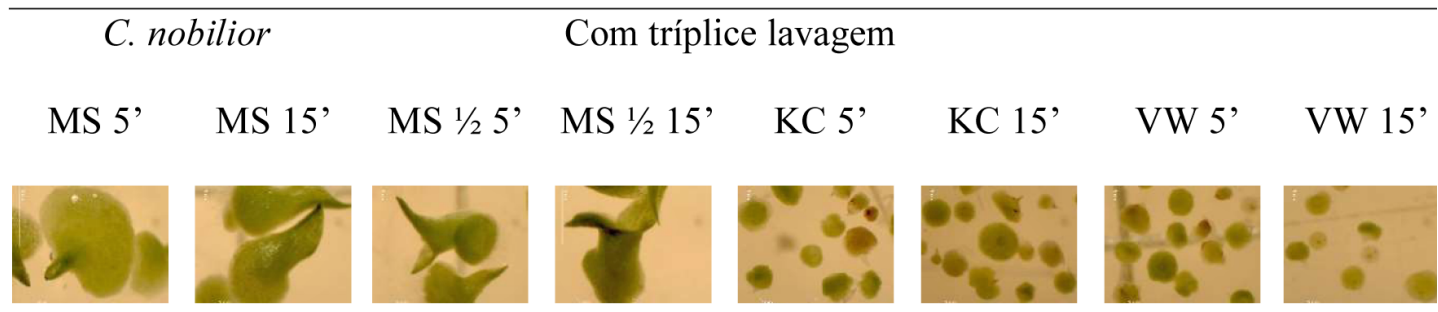

Sem tríplice lavagem
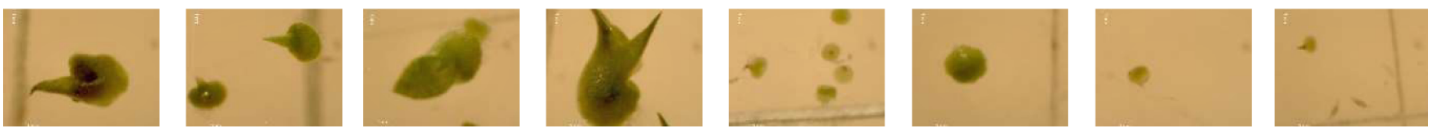

C. lundii

Com tríplice lavagem

MS 15,

$\operatorname{MS~} 1 / 25$,

MS 1/2 15,

$\mathrm{KC} 5$,

$\mathrm{KC} 15$,

VW 5,

VW 15,
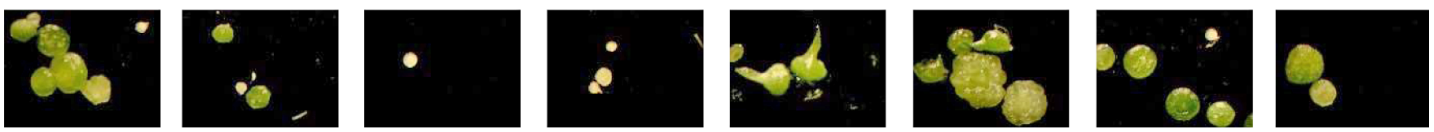

Sem tríplice lavagem
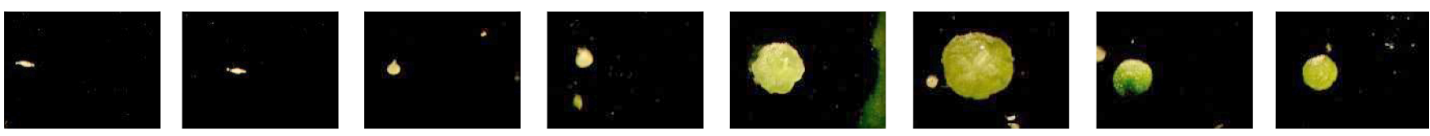

B. tuberculata
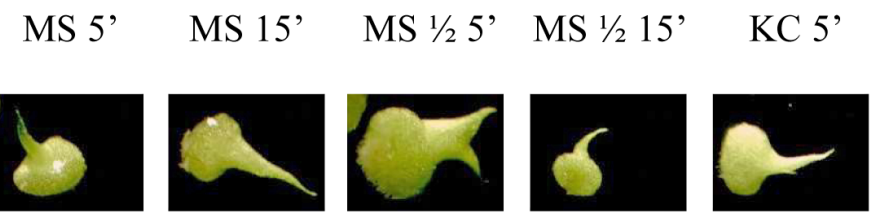

Sem tríplice lavagem
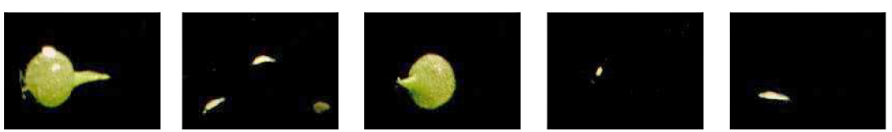
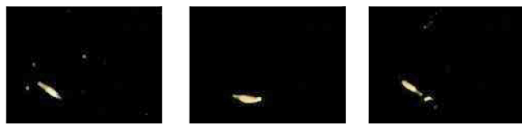

$\overline{1 \mathrm{~mm}}$

Figura 1 - Germinação in vitro de sementes de Cattleya nobilior, Cattleya lundii e Brassavola tuberculata aos 45 dias após a semeadura, em resposta aos meios de cultura (MS = Murashige \& Skoog; MS 1/2 = MS na metade da concentração de sais; $\mathrm{KC}=$ Knudson $\mathrm{C} ; \mathrm{VW}=$ Vacin \& Went), tempo de desinfestação (5 min ou 15 min) e tipo de lavagem utilizados (com ou sem tríplice lavagem).

Figure 1 - In vitro germination of Cattleya nobilior, Cattleya lundii and Brassavola tuberculata at 45 days after sowing, in response to different types of culture media $(\mathrm{MS}=$ Murashige \& Skoog; MS 1/2 = half strength MS; KC = Knudson C; VW = Vacin \& Went), disinfestation time (5 min ou $15 \mathrm{~min}$ ) and type of wash (with or no triple-wash). 


\section{Referências}

Abrão MCR, Jorge J, Pescador R, Melo Ferreira W \& Suzuki RM (2014) Germinação de sementes e desenvolvimento in vitro de plântulas de Cattleya loddigesii Lindl. (Orchidaceae). Revista Brasileira de Biociências 12: 141-147.

Alvarez-Pardo VM, Ferreira AG \& Nunes VF (2006) Seed desinfestation methods for in vitro cultivation of epiphyte orchids from Southern Brazil. Horticultura Brasileira 24: 217-220.

Arditti J \& Ernst R (1992) Micropropagation of Orchids. Wiley-Interscience Publication, New York. 682p.

Barros F, Vinhos F, Rodrigues VT, Barberena FFVA, Fraga CN, Pessoa EM, Forster W, Menini Neto L, Furtado SG, Nardy C, Azevedo CO \& Guimarães LRS (2018) Orchidaceae in Flora do Brasil 2020 em construção. Instituto de Pesquisas Jardim Botânico do Rio de Janeiro. Disponível em $<$ http:// floradobrasil.jbrj.gov.br/reflora/floradobrasil/ FB179>. Acesso em 03 janeiro 2018.

BFG - The Brazil Flora Group (2018) Brazilian Flora 2020: innovation and collaboration to meet Target 1 of the Global Strategy for Plant Conservation (GSPC). Rodriguésia 69: 1513-1527

Batista JAN, Bianchetti LB \& Pelizzaro KF (2005) Orchidaceae da Reserva Ecológica do Guará, DF, Brasil. Acta Botanica Brasilica 19: 221-232.

Campos DM (2002) Orquídea: manual prático de reprodução. $3^{\text {a }}$ ed. Expressão e Cultura, Rio de Janeiro. 143p.

Cardoso JC (2014) Publicação em cultivo in vitro de plantas: qualidade para o avanço científico e tecnológico. Horticultura Brasileira 32: 383-384.

Carneiro LL (2015) Pré-melhoramento genético, floração in vitro e criopreservação de orquídeas nativas do Cerrado. Tese de Doutorado. Universidade Federal de Goiás, Goiânia. 91p.

Chu C \& Mudge KW (1994) Effects of pre-chilling and liquid suspension culture on seed germination of the yellow Lady's slippers orchid (Cypripedium calceolus var. puvescens). Lindleyana 9: 153-159.

Dutra D, Kane M \& Richardson L (2009) Asymbiotic seed germination and in vitro seedling development of Cyrtopodium punctatum: a propagation protocol for an endangered Florida native orchid. Plant Cell, Tissue and Organ Culture 96: 235-243.

Faria RT, Assis AM, Unemoto LK \& Carvalho JFRP (2012) Produção de orquídeas em laboratório. Mecenas, Londrina. 124p.

Ferreira WM \& Suzuki RM (2008) O cultivo in vitro de orquídeas como alternativa para a preservação de espécies nativas ameaçadas de extinção. In: Loiola MIB, Baseia IG \& Lichston JE (eds.) Atualidades, desafios e perspectiva da botânica no Brasil. Imagem Gráfica, Natal. Pp. 67-68.
Hossain MM (2008) Asymbiotic seed germination and in vitro seedling development of Epidendrum ibaguense Kunth (Orchidaceae). African Journal of Biotechnology 7: 3614-3619.

Knudson L (1946) A new nutrient solution for germination of orchid seeds. American Orchid Society Bulletin 15: 214-217.

Mendonça RC, Felfili JM, Walter BMT, Silva Júnior MC, Rezende AV, Filgueiras TS, Nogueira PE \& Fagg CW (2008) Flora vascular do Bioma Cerrado: checklist com 12.356 espécies. In: Sano SM, Almeida SP \& Ribeiro JF (eds.) Cerrado: ecologia e flora. Embrapa Informação Tecnológica, Brasília. Pp. 422-442.

Murashige T \& Skoog FA (1962) A revised medium for rapid growth and bioassays with tobacco tissue culture. Physiology Plantarum 15: 473-497.

Oddie RLA, Dixon KW \& Mccomb JA (1994) Influence of substrate on asymbiotic and symbiotic in vitro germination and seedling growth of two Australian terrestrial orchids. Lindleyana 9: 183-189.

Paul S, Kumaria S \& Tandon P (2012) An effective nutrient medium for asymbiotic seed germination and large-scale in vitro regeneration of Dendrobium hookerianum, a threatened orchid of northeast India. AoB Plants 2012: 1-12.

Pedroso-De-Moraes C, Domingues E, Prezzi LE, SouzaLeal T, Zambon RL, Brescansin RL \& Ramos PAB (2010) Florística e fitossociologia da família Orchidaceae no Centro de Educação Ambiental "Francisco Mendes", município de Mogi Guaçu, SP, Brasil. Scientia Plena 6: 1-5.

Pridgeon AM, Cribb PJ, Chase MA \& Rasmussen FN (2009) Genera Orchidacearum, Epidendroideae (part two). $5^{\text {a }}$ ed. Oxford University Press, Oxford. $664 p$.

Schneiders D, Pescador R, Booz MR \& Suzuki RM (2012) Germinação, crescimento e desenvolvimento in vitro de orquídeas (Cattleya spp., Orchidaceae). Revista Ceres 59: 185-191.

Schuster H, Pedroso-De-Moraes C, Souza-Leal T, Callegari-Correia E, Prezzi L, Domingues E \& Canassa F (2010) Diversidade de Orchidaceae da fazenda Cantagalo, município de Mogi-Mirim, São Paulo. Revista Brasileira de Biociências 8: 242-245.

Silva CS, Araújo LG, Sousa KCI, Carvalho JCB, Gonçalves LA \& Carneiro LL (2016) Cultivo in vitro de Epidendrum nocturnum (Orchidaceae) corrente no Cerrado da Região Centro-Oeste. Rodriguésia 67: 1083-1091.

Silva JAT, Tsavkelova EA, Ng TB, Parthibhan S, Dobránszki J, Cardoso JC, Rao MV \& Zeng S (2015) Asymbiotic in vitro seed propagation of Dendrobium. Plant cell reports 34: 1685-1706.

Soares JS, Rosa YBCJ, Tatara MB, Sorgato JC \& Lemes CSR (2014) Identificação da viabilidade de sementes de orquídeas pelo teste de tetrazólio. Semina Ciências Agrárias: 35: 2275-2284. 
Sorgato JC, Soares JS, Scalon SDPQ, Pereira STS, de Freitas Brotto D \& Ribeiro LM (2020) Does soaking time during disinfestation affect germination rates in Dendrobium?. Bioscience Journal: 36: 42-50.

Suzuki RM, Almeida V, Pescador R \& Ferreira WM (2010) Germinação e crescimento in vitro de Cattleya bicolor Lindley (Orchidaceae). Hoehnea 37: 731-742.
Suzuki RM, Moreira VC, Pescador R \& Ferreira WM (2012) Asymbiotic seed germination and in vitro seedling development of the threatened orchid Hoffmannseggella cinnabarina. In Vitro Cellular \& Developmental Biology - Plant 48: 500-511.

Vacin EF \& Went FW (1949) Some pH in nutrient solutions. Botanical Gazette 110: 605-617.

Editor de área: Dr. Claudio Barbedo Artigo recebido em 26/04/2018. Aceito para publicação em 12/07/2019. This is an open-access article distributed under the terms of the Creative Commons Attribution License. 